\title{
Constructing Psychological Crisis Intervention System in College
}

\author{
Xiuhua $\mathrm{Li}^{1, \mathrm{a} *}$ and Huawei Yang ${ }^{1, b}$ \\ ${ }^{1}$ Student Affairs Department, Technology College, State Grid of China \\ afallingsnow201007@163.coml, blxh.1234560@163.com \\ *The corresponding author
}

Keywords: Psychological crisis, Psychological crisis intervention, Intervention system

\begin{abstract}
At present, the psychological crises occasionally occurring among college students have drawn the wide attention of society as well as set a new challenge for college education. This paper expounds the concepts of psychological crisis and psychological crisis intervention, analyzes the urgency of establishing the psychological crisis prevention and intervention system at college, and addresses ways to establish college students' psychological prevention and intervention system. Through comprehensive discussion, the paper establishes the overall thinking of constructing psychological crisis intervention system at college, which is of guiding significance for the psychological crisis intervention work at college.
\end{abstract}

\section{Introduction}

Along with China's economic development and social changes, college students are faced with increasing challenges from various setbacks and pressures. Some relatively weak students may easily be beset with psychological crisis and even engaged in destructive behaviors, such as drinking, violence, suicide or murder. The harm of the psychological crises is obvious in that they not only endanger students' health and life, but also jeopardize family security, school safety as well as social harmony and stability. It is of great significance to understand the concepts of psychological crises and psychological intervention, recognize the urgency of establishing a psychological crisis intervention system on campus and explore the measures to construct the system in order to reduce the occurrences of crisis events and foster college students' healthy growth.

\section{The Concepts of Psychological Crisis and Psychological Crisis Prevention}

As Caplan, G. the founder of Americ an Psychology, argues, the psychological crisis is the status of psychological unbalance in which individuals can neither avoid nor cope with sudden or serious life events (1964) [1]. If not timely reduced, the psychological crisis will lead to the involved individual's behavioral, emotional and cognitive dysfunction. So the individual in a psychological crisis needs the help of external resources and support to enhance the ability of dealing with misfortune and weather the crisis.

According to G. Caplan, psychological crisis intervention is the timely intervention to instruct the individuals involved in the traumatic events to use the appropriate ways to deal with pressure, weather crises, restore a normal adaptation level and prevent or mitigate the impact of psychological trauma in the future[1]. Some scholars believe that the psychological crisis intervention is a short-term treatment, but as in fact, crisis intervention is a long-term process, and more attention must be paid to the treatment which lasts the prophase, metaphase, and anaphase of the whole process of the crisis.

\section{The Urgency of Establishing Psychological Crisis Intervention System on Campus}

Adolescent college students have high expectations about themselves as well as from society and cherish beautiful dreams for the future. At the same time they are still immature in experiences and values. They tend to become emotionally distressed when confronted by learning and employment 
pressures, adaptation to new learning environments, professional dissatisfaction, complex relationships, bias in self cognition and evaluation as well as inexperience in coping with all kinds of natural setbacks.

According to research on Chinese college students' mental health, the college students who have tendencies toward psychological disorders account for about $20 \% \sim 30 \%$ of the total, those with psychological disorders about $10 \%$, those suffering from serious psychological abnormalities about $1 \%$, and those in the mental sub-health state close to $50 \%$. The whole mental health of college students showed a downward trend[2]. The psychological crisis incidents on college campus also increased yearly and some college students even engaged in extremely bad behavior, such as Ma Jiajue cruel killing of his classmates in 2004, 19 Beijing student suicide cases in 2009, etc.. Psychological crisis prevention and intervention programms have become an important factor influencing campus safety and social stability.

Currently, the central and local education administration departments have paid increasing attention to college students' psychological health needs and have issued a series of relevant documents and measures. Accordingly, colleges and universities, based on their specific situations, have developed psychological crisis contingency plans, established the crisis assistance teams, and built psychological protection networks. With these efforts, they attempted to form a preliminary college psychological crisis prevention and intervention system.

Although certain results have been achieved with the mental health efforts at college, when compared to that in overseas developed countries, our college students' psychological crisis prevention and intervention system is in its infancy, and still faces many difficulties, mainly including a poor awareness about psychological crisis intervention, imperfections in early warning mechanisms, non-specialty in psychological treatment and lower investment in psychological intervention work than is necessary[3]. Therefore, it has become an urgent requirement of colleges and universities to construct a scientific system of psychological crisis prevention and intervention, in order to improve college psychological crisis intervention capacity, raise students' frustration crisis response ability and reduce the occurrences of unfortunate incidents

\section{The Ways to Establish Psychological Crisis Prevention and Intervention System}

Psychological crisis intervention is a systematic and complicated project. Colleges should make the best use of the advantages of education management and mobilize all resources on campus so as to create a psychological crisis prevention and intervention system featuring in sound-organization, timely warning, scientific intervention and effective promotion.

Improving Psychological Crisis Prevention and Intervention Organization. Organization is the basic guarantee for realizing psychological crisis prevention and intervention, and great importance should be attached to the role of the school in establishing and perfecting the organization of the college students' psychological crisis prevention and intervention[3].

Integrating the Psychological Crisis Prevention and Intervention into the Emergency Prevention and Disposal Work. College students' psychological crisis prevention and intervention mechanisms should be established on the basis of moral education, integrated into the emergency prevention and disposal work, and become part of leaders' responsibilities at work, in order to strengthen the leadership and guarantee the allocation of personnel, field and budget.

Playing the Guiding Role of the Mental Health Educating and Consulting Institutions. The mental health educational consultancy institutions should develop the work plan, and keep contact with the relevant agencies and departments in order to timely intervene the student individual or group beset with psychological crisis, and periodically evaluate psychological crisis intervention work.

Equipping Full-time Psychological Crisis Intervention Professionals. Psychological crisis intervention professionals equipped to use scientific methods to handle crises should come into the school moral education work system, and provide guidance for school mental health education and psychological crisis prevention.

Training Counselors, Teachers and Other Education Personnel. Provide professional training to counselors and teachers, improve their theoretical accomplishment and practical operation so that 
each one has the ability of indentifying students in psychological crisis. Furthermore, cultivate student cadres to be psychological members in class and activate their role in the psychological crisis early warning and intervention.

Establishing Crisis Intervention Management Responsibility System. First, every incident of college student suicide or leaving school should be reported in a timely manner; second, any department, class counselor or teacher who is responsible for the incident of a college student suicide or of leaving school should be deprived of excellence assessment qualification; third, the intervention mechanism should be brought into the work appraisal index system.

Bettering College Students' Psychological Crisis Prevention and Early Warnings. Colleges and universities have their unique characteristics of life, learning and education management. The context determines the focus of college students' psychological crisis intervention lies in prevention [3]. Crisis prevention will not only enhance students' ability to cope with crisis, but also increase the resources and strength to resolve the crisis, thus minimizing the occurrences of crisis events. Prevention strategies are put forward as the following:

Popularizing Mental Health Education. The popularization of mental health education is effective for college students' psychological crisis prevention. The purpose of developing college students' mental health education is not only to popularize the basic psychological knowledge, guide students to set up psychological crisis prevention consciousness as well as improve their ability of dealing with the psychological crisis, but also to improve the students' psychological quality and guide them to grow up healthily.

Developing Surveys on College Students' Mental Health. Developing surveys on college students' mental health is the foundation of establishing early warning mechanism. The psychological crises, most of which are gradually formed, have their inner psychological roots. Develop students' psychological surveys, build students' psychological health records, and we will find out some defects in psychological quality, identify the students with psychological problems, and further provide them with purposeful intervention and assistance.

Practicing the Warning Mechanism in Class. Practicing the warning mechanism in class is the key to playing a role of warning mechanisms. Usually, a sign of mental crisis is discovered by some students, a teacher in charge, or a counselor. Therefore, it is important to acknowledge full play to their roles and to educate them on psychological crisis prevention so that they will timely report to the psychological counseling and intervention institutions whenever observing symptoms of psychological crisis on campus.

Solving the Problems Possibly Leading to the Psychological Crisis at Their Inception. Solving the problems possibly leading to the psychological crisis at their inception is the key point of college students psychological crisis preventing. Regulate the student education work and develop procedures for the purpose of solving at the inception the problems such as learning difficulties, troubled relationships, excessive use of network, etc. in order to prevent psychological crisis.

Raising the Level of College Students' Psychological Crisis Intervention. College students, with a higher cultural level, have strong ability to accept new knowledge. Under correct guidance, they can possibly change improper behavior patterns, improve self-awareness, and become social talents [4]. It is very necessary and feasible to raise their level of psychological crisis intervention professionally, hierarchically and multi-directionally.

An Integrated Intervention Support System Involving Family, School and Society. For college students, parent-child relationship crisis deficient education, the uncertainty of the society are the three main categories of psychological crisis sources, and the joint efforts of family, school and society are necessary to solve the students' mental crisis. Therefore, full play must be given to the combined function of all aspects of family, school and society to build up an integrated psychological crisis intervention and support system.

Multiple Ways of Psychological Crisis Intervention. To enhance the effectiveness of intervention, psychological crisis intervention can be realized in the multiple ways including: relief hotline for crisis, counseling interview in the consulting room to dissolve the psychological crisis and psychological intervention on a live chat line on the Internet. 
Professional Involvement in College Students' Psychological Crisis Intervention. From the perspective of psychology, crisis intervention involves psychological consultation and treatment technology to rebuild or restore a psychological balance before the outbreak of the crisis by mobilizing the individual's body potential. Counseling staff must be trained to analyze the external surroundings of the students in crisis, understand their cognitive attitudes, behavior characteristics, assess the severity of the crisis so as to choose the appropriate solution, take timely and effective measures, and eventually lead them gradually to increasing self-knowledge.

Hierarchical Psychological Crisis Intervention. For students at the early stage of a psychological crisis, the psychological intervention can be carried out by providing spiritual support to help them build self confidence in their ability to deal with the crisis, offering an opportunity to release the excessive accumulation of mental energy, increasing hope and optimism, providing selective listening sessions and raising direct suggestions and restrictions according to the actual situation. For students with serious psychological problems, the intervention procedures are as the following: reporting their mental health situation to the education center for evaluation and consultation; paying close attention to their psychological state, carrying out psychological counseling, and providing specialist consultation if necessary; taking effective measures to ensure their personal safety. For students having a tendency toward suicide, set up a group to practice the over-all monitoring of the student and at the same time notify the parents to come to the school..

Establishing the Promotion System for Psychological Crisis Intervention. Crisis resolving is just one target of crisis intervention in colleges and universities. The original purpose of crisis intervention lies in promoting individuals' psychological health and overall growth. Therefore, constructing the promotion system for crisis intervention will provide a promising platform for the crisis intervention work on campus [6].

Constructing Student-in-crisis Tracking Mechanism. The psychological crisis has the characteristic of the repetitive seizures, which can be illustrated by the fact that students having made a suicide attempt tend to choose to commit suicide when facing the next significant setback. Therefore, crisis student tracking mechanism should be established to timely track the psychological health state of high-risk students, and enhance the initiative of crisis intervention.

Establishing Companions' Intervention Mechanism. Psychological crisis events can bring powerful psychological conflict to the classmates of the crisis student. If not effectively handled, this kind of psychological conflict will make them produce acquisition effect to the unhealthy response of negative emotional states. That is to say, crisis is "contagious" to some extent, so it is necessary to provide psychological crisis intervention to the other students who have witnessed the crisis event in order to help them dissolve the negatively psychological impact caused by the crisis, improve their immunity and boost their skills of processing some similar crises.

Founding the Evaluation Mechanism of Crisis Intervention Work. After having come to an end, the crisis intervention work must be evaluated in all aspects, like whether the prevention system played a proper role, the crisis intervention team operated coordinately, the professional intervention techniques adapted to the actual situation in pretention, in order to raise suggestions for improvement and increase operational efficiency.

\section{Conclusion}

In conclusion, as an important part of moral education, the psychological crisis intervention is necessary and feasible for promoting college students' healthy growth, and constructing the psychological crisis intervention system is an all-round, comprehensive project, including improving the intervention organization, bettering early warning, raising the level of intervention and establishing the promotion system. Mental health workers at colleges should adapt to the new situation, explore and practice the crisis intervention system and carry out fruitful work in psychological crisis prevention and intervention services for the healthy growth of college students. 


\section{References}

[1] G. Caplan, Principles of preventive psychiatry, New York: Basic Books, 1964.

[2] Y. D. Wang, The construction of psychological crisis intervention system for college students, Journal of Henan Institute of Science and Technology, vol. 9, pp.116-118. 2010.

[3] R. G. Lou \& J. H. Pan, On College students' psychological crisis prevention and intervention mechanism, China's Higher Education Research, vol. 6, pp. 52-53, 2006.

[4] F. Liu, Prevention strategies for establishing psychological crisis intervention in universities. Journal of Xianning College, vol. 8, pp.146-148, 2007. 